\section{UNDERSTANDING QUALITY IN HOME BASED BRASSWARE MANUFACTURING UNITS IN INDIA}

\begin{tabular}{|l|l|l|}
\hline Kapil Deo Prasad & Sanjay Kumar Jha & Ritesh Kumar Singh \\
Department of Production Engineering & Department of Production Engineering & Department of Production \\
Bilra Institute of Technology, Patna & Bilra Institute of Technology, & Engineering \\
Campus & Mesra, Ranchi & Bilra Institute of Technology, \\
$\begin{array}{l}\text { Patna, Bihar, Pin Code 800014, India } \\
\text { kapildprasad@ bitmesra.ac.in }\end{array}$ & Ranchi, Jharkhand, Pin Code 835215, & Mesra, Ranchi \\
& $\begin{array}{l}\text { India } \\
\text { sanjujha@ @hotmail.com }\end{array}$ & Ranchi, Jharkhand, Pin Code 835215, \\
\hline
\end{tabular}

\begin{abstract}
Production process and technology practiced along with quality practices followed in brassware manufacturing units in India are age old, mainly home based and are labour oriented. The modern technological developments have not been incorporated due to financial limitations. The rudimentary quality practices too are resulting in high percentage of defective brassware products. This aspect requires analysis of such units in depth so as to develop new concepts or interpretations of quality in home based brassware manufacturing units. Quality has been considered as the primary source of a competitive advantage and survival of the business and has been defined in a variety of ways - one of them defining quality as an enhancement to the traditional way of doing business. The major contribution of this paper lies in redefining quality for home based brassware units. The determinants of quality in the context of home based brassware manufacturing are work place environment, motivational provisions and dependability that require continuous improvement.
\end{abstract}

Key Words: Production process; Technology; Quality; Brassware, Manufacturing, Business.

\section{INTRODUCTION}

Brassware manufacturing units have existed in India since ancient times, practiced mostly by tribal people. Brassware manufacturing is an integral part of rural industrial activity of the country. These units' production activities are labour oriented. They contribute significantly towards industrial employment and also as our link to ancient heritage and culture. They contribute about $15 \%$ of total output of smallscale industries, employing about $40 \%$ of the total workforce in this sector [1]. These units are based on traditional skills and simple manufacturing processes that are carried mostly by hand tools and in few cases by simple machines. Lack of mechanization and technology adaptation are putting these brassware manufacturing units into disadvantageous position vis-a-vis industries in organized sector. This is threatening the very existence of these units. Being labour intensive, these brassware manufacturing units are employment generating, capital saving and capable of operating on a decentralized basis in rural areas.

\section{HOME BASED BRASSWARE MANUFACTURING INDUSTRY}

The brassware industry in India is centuries old. The prominent brassware manufacturing clusters in India are Moradabad (Uttar Pradesh), Aligarh (Uttar Pradesh),
Mirzapur (Uttar Pradesh), Amrali (Gujarat), Jamnagar (Gujarat), Mutch (Gujarat), Porbandar (Gujarat), Surendranagar (Gujarat), Dhrangadra (Gujarat), Pareo (Bihar), Jariagarh (Jharkhand), Bastu (Chhattisgarh), Raigarh (Chhattisgarh), Faridabad (Haryana), Rewari (Haryana), Sonepat (Haryana), Yamunanagar (Haryana), Warrangal (Andhra Pradesh), Chittoan (Andhra Pradesh), Hajo near Kampup (Assam), Khurda (Orissa), Indipur (Orissa), Buditi (Orissa), Benkura (West Bengal), Birbhum (West Bengal), Kisnagar (West Bengal), and so on.

There are large numbers of brassware products being made by the industry. The number of these products amounts to hundreds as reported by exporters and manufactures. All the exporters trade in different kinds of products with a variety of designs according to the requirements of importers. Some of the products being made include candle stands, cutlery items, fruit and vegetable containers of different sizes and designs, bowls of different sizes and designs, decorative items, etc. Brassware products for Domestic use in India include utensils like, Thali, Lota, Bhagauna, Kathot, Kalchul, Karahi, Katora, Glass, Tastari etc., and brassware articles for religious work and marriage occasions over and above the products made for export. Industrial Brassware Products include Building Hardware, Sanitary \& Bathroom fittings, Electrical accessories, Automobile parts, Agricultural components etc. and various items for different applications.

Almost all enterprises in the home based brassware industry can be said to be operating at three levels [2]. At the bottom level are the household units that work for small manufacturers (locally known as karkhanedars) who in turn obtain orders from exporters. Therefore, these household units are subcontracted by karkhanedars. Karkhanedars are at the second level and at the top level are exporters. Karkhanedars normally have their own units that undertake operations like scraping, welding and polishing in-house whereas they subcontract the work of casting to household units that undertake the melting and casting operations. In many cases, karkhanedars also subcontract the work of scraping, welding and polishing to household units that exist for this purpose. In addition to the above links, there are contractors for undertaking jobs like polishing, plating and packaging. They supply workers mainly to exporters to undertake these works on contract. The exporters normally provide machines and infrastructure housed on their own premises. 
Most of the brassware manufacturing units are home based and cluster based. The cluster development approach can play a vital role in the development of the micro, small and medium enterprises (MSMEs) in India [3-4-5]. Production process and technology practiced along with quality practices followed in these units are age old. The modern technological developments have not been incorporated due to financial limitations. The rudimentary quality practices too are resulting in high percentage of defective brassware products. The productivity achieved by bigger brassware manufacturer is quite high compared to the rural artisans. Therefore, there is a need to explore and identify appropriate technologies and quality practices, adaptation of which could ensure improvement in the level of quality and hence productivity achieved. To address these challenges some new concepts or interpretations of quality in home based brassware manufacturing units have been developed in the following sections.

\section{QUALITY}

According to ISO 8402: 1994 [6] - "Quality is the totality of characteristics of an entity that bears on its ability to satisfy stated and implied needs." In other words Quality is the degree to which a set of inherent characteristics fulfils requirements - as per ISO $9000: 2000$ [7].

Here, characteristics implies functional efficiency, appearance, ease of installation and operation, safety, reliability, maintainability, running \& maintenance costs etc. An entity may be an activity, a process, a product, an organisation, a system, a person or any combination of these. Stated needs implies specification, e.g., length, dia. \& material of a part, say, shaft. "Implied needs" means surface finish, no dents on the surface, rounded or chamfered edges.

Quality is a relative term and is generally explained with reference to the end use of the product. Quality is defined as fitness for purpose. For example, a good quality car lifting jack may prove itself a bad quality product when tried on a five or seven and a half tonne vehicle.

A particular sector of population may say that "Khadi" is best quality cloth where as another may say that "cotton" gives best quality cloth. Yet another sector may say it is "silk". This proves that there is no absolute quality. It differs from a particular sector of population to another and quality is as man perceives it. Similarly, for a sector of the population Maruti Alto or a compatible car may be the best selection where as for another sector of the population Mercedes Benz may be the best selection of a car. In India there is market for different qualities of a product and one can sell from a one-bed room apartment to a big bungalow.

The quality of products which are being made available to different sectors of population is increasing in our country day-by-day. So, it is not the per capita income which determines the richness of a country, but it is the type of quality products which are available for different sectors of a national population. Therefore, it is the quality of life in a nation which should be used to judge the earning capacity of a country. It also shows that the quality of a product changes with time.
Harvey and Green distinguish three definitions of quality that are relevant to the issue of quality assurance (QA): as value for money, as fit for the espoused purpose, and as transforming [8]. For example, in context of assuring and enhancing quality of teaching and learning in an institution, value for money reflects a quality institution is one that produces more graduates for little public finance, more peer-reviewed publications per capita academic staff, has more Ph.D.s on its staff, and a strategic plan that signals high levels of self-funded activities. Quality as fit for the espoused purpose reflects the purpose of students getting to learn effectively, and to accredit that they have learnt to the publicly recognizable standards. There may be several purposes of an institution or a university, however teaching and research are the most important purposes. Quality as transforming reflects quality teaching that transforms the students' perception of world and the way they go about applying their knowledge for solving real world problems. Quality also transforms the teachers' perception of their role as teacher and the culture of the institution itself.

Quality means different to different people. To the design person it means setting up standards for a product which will meet the needs of customers, whereas to manufacturing persons it means producing products which will meet the design specifications set up by the designer. But finally when the product comes in hands of customer, quality means whether the product performs to his satisfaction or not. Thus, quality may be achieved by dividing it into three groups: Quality of Design, Quality of Conformance, and Quality of Performance.

\section{QUALITY OF DESIGN}

After market survey the company comes to know the quality of products which the customer needs and this information is transferred to design and engineering persons. Design department conceives the product which will satisfy the customer needs. The design department transfers the design requirements of the product into product specifications, like dimension in $\mathrm{mm}$, material as Stainless Steel, tensile strength in $\mathrm{kg}$ per square $\mathrm{mm}$, or hardness in Rockwell scale etc. Then the engineering department improves upon the product quality by giving the limits and tolerances on the specifications, by providing process specifications, quality control measures to be taken during manufacturing and final release of the manufactured product to the customer.

\section{QUALITY OF CONFORMANCE}

After designing a part or a product it is the responsibility of the manufacturing department to produce the parts and the product as per the specifications, limits and tolerances provided by the design and engineering departments. The parts and the product are inspected at various stages of manufacturing and the processes are controlled to achieve this goal. The complaint given by the quality control department is that the product produced does not conform to the specifications, not only because of the manufacturing department, but also because of the design and engineering departments, due to the limits and tolerances provided by them. The degraded quality of product is produced because 


\section{, \\ ELK \\ Asia Pacific Journals}

of many reasons such as production in night shift, disability of the manufacturing machines and processes, unsuitability of quality control instruments and man power etc. If the quality of conformance is not good, the cost of the product goes up. Hence a proper manufacturing process is necessary.

\section{QUALITY OF PERFORMANCE}

After design and manufacturing when the product finally comes in the hands of the customer, he is the final judge to assess whether the product meets his needs or not. If he is satisfied with the product performance, quality of the product is good for him. Quality of product can be judged by the share of the market which the product wins, the percentage of product complaints, product repair and product maintenance frequency. The feedback obtained from the customers of quality of performance on the above mentioned criteria is given back to design and engineering departments and also to the manufacturing department. If the design of the product is not good and a number of product failures is because of bad design of the product, the design is reviewed and a better design is evolved. If the fault is in the quality of conformance, the manufacturing process may be changed or better machines may be used. The quality control process is made strict and the new improved product is launched in the market.

\section{QUALITY IN HOME BASED BRASSWARE MANUFACTURING INDUSTRY}

The above deliberations show that quality is defined mainly as meeting technical specifications. However, in the context of brassware manufacturing units it is to be understood as the combination of socio-technical process towards doing the right things (externally), every right thing (internally), first time and all the time, with economic viability considered at each stage of each process. Quality has been defined in a variety of ways: a quest for excellence, creating the right attitudes and controls to make prevention possible by increased efficiency and effectiveness. In its broadest sense, quality is about meeting customer expectations. The quest for quality is continuous improvement in the areas of work place environment, motivational provisions, and dependability [9] in the context of brassware manufacturing units.

Quality has been understood as an enhancement to the traditional way of doing business [9-10]. It is a proven technique to guarantee survival in world-class competition. The impact of quality on business performance has been considered by a number of research studies as the primary source of a competitive advantage. The determinants of quality in the context of home based brassware manufacturing are work place environment, motivational provisions and dependability, whose characteristics are listed below:

- Work Place Environment

○ Good house-keeping

- Safety concerns

- Health concerns

- Remuneration concerns

\section{ELK Asia Pacific Journals - Special Issue}

ISBN: 978-81-930411-4-7

○ Working hour concerns

- Motivational provisions

○ Financial support concerns

- Professional market development concerns

- Professional market access concerns

- Government support for clusters concerns

- Brass scrap recycling concerns

- Dependability

○ Worker availability concerns

- Karkhanedars' availability concerns in case of need

- Timely services concerns

- Mistake proofing concerns

These characteristics are to be mapped on the scale of 1 to 5 , where ' 1 ' stands for "worst in industry," and ' 5 ' stands for "best in industry" in respect of brassware manufacturing eco-system.

\section{CONCLUSION}

In this paper the status of the home based brassware manufacturing has been described and the meaning of quality in this context has been defined. This paper also presents how to define and improve quality for home based brassware manufacturing. An effort has been made to look into the actual issues of the practitioners of home based brassware manufacturing that will lead to a better explanation and understanding of the quality problems and solutions in this context. For the most part the people are focused on their job to a great extent. When people know what is expected, how they are performing, and that their contribution is properly documented and recognized without any biasness, they tend to become better, happier workers - the kind everyone is looking for. And they tend to stay longer with performance in pursuit of productivity and quality for the business.

\section{REFERNCES}

[1] M.K. Sharma, and R. Bhagwat, "Performance measurement system: case studies from SMEs in India," Int. J. Productivity and Quality Management, Vol. 2, No. 4, pp. 475-509, 2007.

[2] Humphery John, and Schmitz Hubert, "Principles for promoting clusters \& networks of SMEs," No. 1, Discussion Paper, UNIDO (SME Programs), October, 1995.

[3] AS Saleh, and NO Ndubisi, "SME Development in Malaysia: Domestic and Global Challenges," Working Paper 06-03, Department of Economics, University of Wollongong, 2006.

[4] Peter Knorringa, and Meyer-Stamer Jörg, "New dimensions in local enterprise cooperation and development: from clusters to industrial districts," New Approaches to Science and Technology Cooperation and Capacity Building. New York, Geneva: United Nations (atas XI), 1998.

[5] V. P. Kharbanda, "Facilitating innovation in Indian small and medium enterprises-The role of clusters," CURRENT SCIENCE-BANGALORE, Vol. 80, No. 3, pp. 343-348, 2001. 


\section{Asia Pacific Journals}

[6] International Organization for Standardization, ISO 8402: 1994: Quality Management and Quality Assurance-Vocabulary. International Organization for Standardization, 1994.

[7] International Organization for Standardization, ISO 9000: 2000 - Fundamentals \& Vocabulary. International Organization for Standardization, 2000.

[8] Lee Harvey, and Diana Green, "Defining quality," Assessment \& evaluation in higher education, Vol. 18, No. 1, pp. 9-34, (1993).

[9] R. R. Lakhe, and R. P. Mohanty, "Understanding TQM," Production Planning \& Control, Vol. 5 No. 5, pp. 426-441, 1994.

[10] M. Foster, and S. Whittle, "The quality management maze," TQM Magazine, Vol. 1 No. 3, pp. 143-148, 1989. 